\title{
AN EXPERIMENTAL AND THEORETICAL APPROACH FOR THE CARBON DEPOSITION PROBLEM DURING STEAM REFORMING OF MODEL BIOGAS
}

\author{
Grzegorz Brus, Remigiusz Nowak, Janusz S. Szmyd \\ AGH University of Science and Technology, Faculty of Energy and Fuels, Kraków, Poland \\ e-mail:brus@agh.edu.pl; remigius@agh.edu.pl \\ Yosuke Komatsu \\ Shibaura Institute of Technology, Graduate School of Engineering and Science, Fukasaku, Saitama, Japan \\ SHINJi KImiJima \\ Shibaura Institute of Technology, College of Systems Engineering and Science, Fukasaku, Saitama, Japan
}

\begin{abstract}
The conversion of biogas to electricity presents an attractive niche application for solid oxide fuel cells (SOFCs). A number of attempts have been made to use biogas as a fuel for high temperature fuel cell systems such as SOFCs. Biogas can be converted to a hydrogen-rich fuel in a reforming process which can use steam or carbon dioxide as the reforming agent. Conventionally, the reforming process is conducted at around $850^{\circ} \mathrm{C}$ using several different catalysts depending on application. Biogas naturally contains the reforming agent, carbon dioxide, however, for typical biogas the content of carbon dioxide is insufficient to conduct the reforming process safely. Fore those cases, steam is added to prevent carbon deposition. Carbon formation occurs between the catalyst and the metal support, creating fibers which damage the catalytic property of the reactor. A number of papers have dealt with the problem of carbon deposition during both methane steam reforming and dry reforming. However, from the standpoint of solid oxide fuel cells, not every carbon-free condition is optimal for its operation. This paper treats this subject, explaining the mechanism of carbon formation during the steam reforming of biogas and using a numerical analysis to determine efficient and carbon-free working conditions.
\end{abstract}

Keywords: reforming system, numerical modelling, heat transport phenomena, biogas, carbon deposition

\section{Introduction}

While conventional SOFCs using hydrogen or methane as a fuel are slowly approaching commercialisation, attempts have been made to use biogas as a fuel for SOFCs (Effendi et al., 2005). Internal reforming SOFCs running on biogas are environmentally friendly, compact, and cost-effective. Biogas contains the natural reforming agent $\mathrm{CO}_{2}$ and can therefore be fed into the SOFC system directly or with a small addition of steam. The results obtained by Nishino and Szmyd (2010) are, at least from the point of view of performance and thermal management, promising for the future use of biogas in indirect internal reforming SOFC systems. Furthermore, using biogas does not contribute to $\mathrm{CO}_{2}$ emissions and has great potential for reducing them (Kolbitsch et al., 2008). However, in order to run SOFCs on biogas, it is very important to establish carbon-free conditions and design an effective reforming process for safe and stable hydrogen production.

Carbon deposition during the reforming process has been studied by others (Yang and Yang, 1986; Claridge et al., 1993; Berman et al., 2005; Murray et al., 2008; Timmermann et al., 2007; Assabumrungrat et al., 2005, 2006). Yang and Yang (1986) studied carbon deposition during 
high temperature hydrocarbon processing. It was reported that carbon deposition is a significant problem during the decomposition of hydrocarbons at elevated temperatures and might lead to the deactivation of the catalyst (Yang and Yang, 1986). It was also found that hydrogen has a retarding effect on carbon deposition (Yang and Yang, 1986). Claridge et al. (1993) investigated the influence of different catalysts on carbon deposition by thermal cracking of methane and carbon monoxide disproportionation. Berman et al. (2005) found that the relative rate of carbon deposition follows the order $\mathrm{Ni}>\mathrm{Pd}>\mathrm{Rh}>\mathrm{Ir}, \mathrm{Ru}$. Xu et al. (2010) conducted an experimental analysis of the biogas reforming process resulting from process optimisation and selection of carbon-free conditions. Their studies indicated that the optimum ratio of carbon dioxide to methane was equal to 3 . Under the selected optimum conditions, the catalyst exhibited excellent activity without significant deactivation of more than $100 \mathrm{~h}$, and achieving $85 \mathrm{~mol} \%$ of hydrogen yield and a methane conversion rate of $87.7 \mathrm{~mol} \%$. The results of Claridge et al. (1993) showed that the amount of carbon from pure carbon monoxide via the Boudouard reaction is very low compared with the amount deposited from the methane decomposition reaction $(20$ times less) at $1050 \mathrm{~K}$. However, at a lower temperature of $670 \mathrm{~K}$, the Boudouard reaction was found to be the most thermodynamically favoured carbon forming reaction (Claridge et al., 1993). Suppression of carbon deposition in the reforming process of methane with carbon dioxide was previously studied by Osaki et al. (1994). Their (Osaki et al., 1994) studies on non-classical catalysts indicate that when aided with the addition of an alkaline salt, the activity of $\mathrm{Ni}$ on the decomposition of $\mathrm{CH}_{4}$ decreases. The effect of doping nickel with small amounts of metals was studied by Trimm (1997). It was found that a small concentration of metals or sulphur on the nickel surface significantly reduces the formation of coke (Trimm 1997). The roles of methane cracking and carbon monoxide disproportionation were studied experimentally by Murray et al. (2008) who showed that when feeding pure methane over an SOFC anode, no carbon was observed for temperatures lower than $973 \mathrm{~K}$. However, the amount of carbon formed as a result of methane pyrolysis increased along with the process temperature (Murray et al., 2008). Research of Murray et al. (2008) also showed that for a given temperature, the type of catalyst used plays the key role and that a low $\mathrm{CO} / \mathrm{CO}_{2}$ ratio suppresses carbon deposition through carbon monoxide disproportionation. A pre-reformer must therefore be used to prevent the $\mathrm{CO} / \mathrm{CO}_{2}$ ratio from becoming too low (Murray et al., 2008). Timmermann et al. (2007) indicated that for a Ni/YSZ cermet-based SOFC anode, the measured magnitude of coke formation was significantly lower than thermodynamic equilibrium calculations. The conclusion indicates that a slow reaction rate explicitly inhibits carbon formation (Timmermann et al., 2007). Theoretical thermodynamic analyses of carbon formation during the reforming process of different fuels have been carried out by several groups (Assabumrungrat et al., 2005, 2006; da Silva et al., 2009). Assabumrungrant et al. predicted the thermal boundary of carbon deposition for an SOFC with direct internal reforming when fueled by methanol (Assabumrungrat et al., 2005). The results indicated that carbon formation can be minimised by increasing the steam/methanol ratio or by increasing the operating temperature (Assabumrungrat et al., 2005). They showed that in the case of dry reforming, working at high temperatures significantly reduced the required ratio between carbon dioxide and methane (Assabumrungrat et al., 2006). Lima da Silva et al. (2009) conducted a thermodynamic analysis of the ethanol/water system, using the Gibbs energy minimisation method. A mathematical relation between Lagrange multipliers and the carbon activity in the gas phase was deduced (da Silva et al., 2009). The results indicated that there is no effect of the inlet steam/ethanol ratio on carbon activity values, and that such a system is highly favourable to carbon formation.

A number of studies on carbon deposition during reforming processes have been carried out by different research groups. However, there has been little research on carbon formation during the reforming of biogas with the addition of steam, especially as regards the optimal working conditions. In this study, a thermodynamic analysis of the biogas reforming process has 
been conducted. The optimal working conditions have been juxtaposed with a carbon formation regime, and safe conditions have been selected. In the present study, the biogas fed into the reformer is assumed to be composed of $\mathrm{CH}_{4}$ and $\mathrm{CO}_{2}$, and the molar percentage of $\mathrm{CH}_{4}$ contained in the biogas varied within the range $0 \%$ to $75 \%$. It is also assumed that the biogas is fed into the reformer together with steam $\left(\mathrm{H}_{2} \mathrm{O}\right)$. With this assumption, the reforming of model biogas with steam is a combined process of dry and steam reforming, with an associated water shift reaction. The numerical model presented in this paper can be implemented for a global numerical study on the thermal and electrochemical characteristics of a solid oxide fuel cell system employing the steam reforming of biogas.

\section{Thermodynamic analysis of carbon formation}

The rate and magnification of carbon deposition might be different from one catalyst to another (Berman et al., 2005; Timmermann et al., 2007), however the border of carbon deposition can be determined at the equilibrium conditions. The process of biogas reforming with steam can be described by the following three reactions (Kolbitsch et al., 2008; Effendi et al., 2005; Brus et al., 2012):

- methane/steam reforming reaction

$$
\mathrm{CH}_{4}+\mathrm{H}_{2} \mathrm{O} \rightleftharpoons 3 \mathrm{H}_{2}+\mathrm{CO}
$$

— dry reforming reaction

$$
\mathrm{CH}_{4}+\mathrm{CO}_{2} \rightleftharpoons 2 \mathrm{H}_{2}+2 \mathrm{CO}
$$

- shift reaction

$$
\mathrm{CO}+\mathrm{H}_{2} \mathrm{O} \rightleftharpoons \mathrm{H}_{2}+\mathrm{CO}_{2}
$$

Chemical equilibrium is represented by the equilibrium constants of each reaction, which is a function of temperature

$$
\begin{array}{ll}
K_{s t}=\frac{p_{\mathrm{CO}} p_{\mathrm{H}_{2}}^{3}}{p_{\mathrm{CH}_{4}} p_{\mathrm{H}_{2} \mathrm{O}}}=\exp \left(-\frac{\Delta G_{s t}^{0}}{R T}\right) & K_{d r y}=\frac{p_{\mathrm{CO}}^{2} p_{\mathrm{H}_{2}}^{2}}{p_{\mathrm{CH}_{4}} p_{\mathrm{CO}_{2}}}=\exp \left(-\frac{\Delta G_{d r y}^{0}}{R T}\right) \\
K_{s h} & =\frac{p_{\mathrm{CO}_{2}} p_{\mathrm{H}_{2}}}{p_{\mathrm{CH}_{4} p_{\mathrm{H}_{2} \mathrm{O}}}}=\exp \left(-\frac{\Delta G_{s h}^{0}}{R T}\right)
\end{array}
$$

where $\Delta G_{s t}^{0}, \Delta G_{d r y}^{0}$, and $\Delta G_{s h}^{0}$ are the changes in the standard Gibbs free energy of, respectively, the methane/steam reforming, dry reforming, and shift reaction $\left[\mathrm{J} \mathrm{mol}^{-1}\right], R$ is the universal gas constant $8.314482 \mathrm{~J} \mathrm{~mol}^{-1} \mathrm{~K}^{-1}$, and $\mathrm{T}[\mathrm{K}]$ is the reaction temperature. However, thermodynamically favourable carbon deposition should be considered in the analysis aside from methane/steam reforming, dry reforming, and shift reaction (the reactions (2.1), (2.2), and (2.3)). The equilibrium gas mixture consists of $\mathrm{CH}_{4}, \mathrm{H}_{2} \mathrm{O}, \mathrm{CO}, \mathrm{CO}_{2}$, and $\mathrm{H}_{2}$, which at a particular temperature and total pressure reach thermodynamic equilibrium. Carbon formation can therefore occur as the effect of the following reactions (York et al., 2007):

- methane decomposition

$$
\mathrm{CH}_{4} \rightleftharpoons 2 \mathrm{H}_{2}+\mathrm{C}
$$

— carbon monoxide disproportionation

$$
2 \mathrm{CO} \rightleftharpoons \mathrm{CO}_{2}+\mathrm{C}
$$


The chemical equilibrium of reactions (2.5) and (2.6) is represented by the equilibrium constants of each reaction and is equal to the ratio between the partial pressures of the reactants and the products

$$
K_{m}=\frac{p_{\mathrm{H}_{2}}^{2} a_{m}}{p_{\mathrm{CH}_{4}}}=\exp \left(-\frac{\Delta G_{m}^{0}}{R T}\right) \quad K_{c}=\frac{p_{\mathrm{CO}_{2} a_{c}}}{p_{\mathrm{CO}}^{2}}=\exp \left(-\frac{\Delta G_{c}^{0}}{R T}\right)
$$

The co-existence of $\left(\mathrm{CO} / \mathrm{CO}_{2}\right)$ and $\left(\mathrm{H}_{2} / \mathrm{CH}_{4}\right)$ in the gas product of reactions (2.1), (2.2) and (2.3) suggests the course of reactions (2.5) and (2.6) with carbon deposition. The carbon activities $a_{m}$ and $a_{c}$ defined in Eq. (2.7) can be used to determine the possibility of carbon formation (Assabumrungrat et al., 2005)

$$
\alpha_{m}=\frac{p_{\mathrm{CH}_{4}} K_{m}}{p_{\mathrm{H}_{2}}^{2}} \quad \alpha_{c}=\frac{p_{\mathrm{CO}}^{2} K_{c}}{p_{\mathrm{CO}_{2}}}
$$

When the parameter $\alpha>1$, the system is not in equilibrium, reactions (2.5) and (2.6) are shifted to the right side, and carbon is formed.

When the parameter $\alpha=1$, the reactions are in the state of equilibrium, and when $\alpha<1$, carbon formation is thermodynamically impossible. The parameters $\alpha_{m}$ and $\alpha_{c}$ limited to the range 0 to 1 will directly describe the carbon chemical activity where $\alpha_{m}=\alpha_{c}=1$ responds to carbon in the solid form. Figure 1a presents the mechanism of carbon deposition. The straight line describes the equilibrium in the hydrogen-to-methane ratios for thermal cracking of methane. The dots correspond to the calculated partial pressures of methane and hydrogen for different $S C$ ratios during the equilibrium reforming process. When $\alpha>1$ (marked as (1)), the reaction attempts to reach equilibrium by lowering the partial pressure of the methane. The reaction is therefore shifted to the right side and carbon is formed. The opposite is true of the case marked (2) in Fig. 1a: the reaction seeks equilibrium by raising the partial pressure of the methane. The reaction is shifted to the left side and carbon formation is thermodynamically impossible (Assabumrungrat et al., 2005). As can be seen in Fig. 1b, similar conclusions can be reached for carbon monoxide disproportionation.
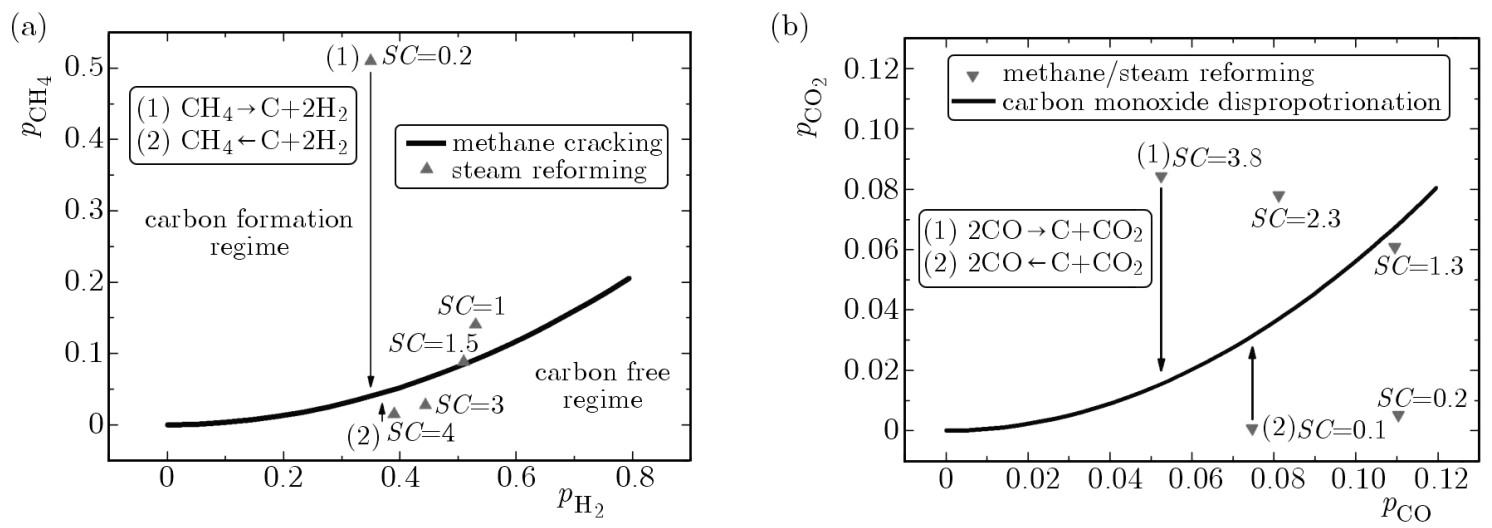

Fig. 1. Equilibrium partial pressures of: (a) methane and hydrogen for methane thermal cracking, (b) equilibrium partial pressures of carbon monoxide and carbon dioxide during carbon monoxide disproportionation

\section{Numerical model and calculating procedure}

In the present study, the biogas fed into the reactor is assumed to be composed of $\mathrm{CH}_{4}$ and $\mathrm{CO}_{2}$. It is assumed that other biogas components such as sulfur, organosilicon, volatile organic compounds and others impurities have been removed before the inlet of the reformer, and the molar 
percentage of $\mathrm{CH}_{4}$ contained in the biogas is varied to model different dilatation (quality) of the biogas. The outlet composition per 1 mole of methane can be calculated from the stoichiometry of reactions (2.1), (2.2) and (2.3). The molar flow rate of each chemical component participating in the fuel reforming process in the reformer can be expressed by assuming $x$ as the conversion rate of methane/steam reforming reaction, $y$ as the rate of $\mathrm{CO}$ consumed by the steam shifting reaction and $z$ as the conversion rate of $\mathrm{CH}_{4}$ through the dry reforming reaction (see Table 1). Variations of the molar flow rate of carbon monoxide, denoted as $x-y+2 z$, are produced

Table 1. Changes of chemical components inside the fuel reformer

\begin{tabular}{|c|c|c|c|c|c|}
\hline $\begin{array}{c}\text { Gas } \\
\text { symbol }\end{array}$ & $\begin{array}{c}\text { Inlet } \\
{[\mathrm{mol}]}\end{array}$ & $\begin{array}{c}\text { Steam } \\
\text { reforming }\end{array}$ & $\begin{array}{c}\text { Shift } \\
\text { reaction }\end{array}$ & $\begin{array}{c}\text { Dry } \\
\text { reforming }\end{array}$ & $\begin{array}{c}\text { Outlet } \\
{[\mathrm{mol}]}\end{array}$ \\
\hline \hline $\mathrm{CH}_{4}$ & 1 & $-x$ & 0 & $-z$ & $1-x-z$ \\
\hline $\mathrm{H}_{2} \mathrm{O}$ & $S C$ & $-x$ & $-y$ & 0 & $S C-x-y$ \\
\hline $\mathrm{H}_{2}$ & 0 & $3 x$ & $y$ & $2 z$ & $3+y+2 z$ \\
\hline $\mathrm{CO}$ & 0 & $x$ & $-y$ & $2 z$ & $x-y+2 z$ \\
\hline $\mathrm{CO}_{2}$ & $C C$ & 0 & $y$ & $-z$ & $C C+y-z$ \\
\hline \multicolumn{7}{|c|}{ Total } & $1+S C+C C+2 x+2 z$ \\
\hline
\end{tabular}

by the fuel reforming reaction and dry reforming and consumed by the steam shifting reaction (see Table 1). Thus the partial pressures of each chemical species caused by the methane/steam reforming reaction, dry reforming and shift reaction are calculated as follows

$$
\begin{array}{ll}
p_{\mathrm{CH}_{4}}=\frac{1-x-z}{1+S C+N C+2 x+2 z} P & p_{\mathrm{H}_{2} \mathrm{O}}=\frac{S C-x-y+2 z}{1+S C+N C+2 x+2 z} P \\
p_{\mathrm{H}_{2}}=\frac{3 x+y+2 z}{1+S C+N C+2 x+2 z} P & p_{\mathrm{CO}}=\frac{x-y+2 z}{1+S C+N C+2 x+2 z} P \\
p_{\mathrm{CO}_{2}}=\frac{C C+y-z}{1+S C+N C+2 x+2 z} P &
\end{array}
$$

where $P$ is the total pressure $[\mathrm{Pa}], S C$ is the ratio between supplied steam and methane, $C C$ is the ratio between supplied carbon dioxide and methane. The equilibrium gas composition can be calculated from

$$
\begin{aligned}
& f_{1}(x, y, z)=K_{s t} p_{\mathrm{CH}_{4}} p_{\mathrm{H}_{2} \mathrm{O}}-p_{\mathrm{CO}} p_{\mathrm{H}_{2}}^{3} \\
& f_{2}(x, y, z)=K_{d r y} p_{\mathrm{CH}_{4}} p_{\mathrm{CO}_{2}}-p_{\mathrm{CO}}^{2} p_{\mathrm{H}_{2}}^{2} \\
& f_{3}(x, y, z)=K_{s h} p_{\mathrm{CH}_{4}} p_{\mathrm{H}_{2} \mathrm{O}}-p_{\mathrm{CO}_{2}} p_{\mathrm{H}_{2}}
\end{aligned}
$$

To solve the system of nonlinear equations (3.2), the Newton method has been used. In each iteration, the system of linear equations has been solved using the current Jacobian matrix $\mathbf{J}$ as it is presented below

$$
\underbrace{\left[\begin{array}{l}
f_{1}(x, y, z) \\
f_{2}(x, y, z) \\
f_{3}(x, y, z)
\end{array}\right]}_{\mathbf{f}(x)}=\underbrace{\left[\begin{array}{lll}
\frac{\partial f_{1}(x, y, z)}{\partial x} & \frac{\partial f_{1}(x, y, z)}{\partial y} & \frac{\partial f_{1}(x, y, z)}{\partial z} \\
\frac{\partial f_{2}(x, y, z)}{\partial x} & \frac{\partial f_{2}(x, y, z)}{\partial y} & \frac{\partial f_{2}(x, y, z)}{\partial z} \\
\frac{\partial f_{3}(x, y, z)}{\partial x} & \frac{\partial f_{3}(x, y, z)}{\partial y} & \frac{\partial f_{3}(x, y, z)}{\partial z}
\end{array}\right]}_{\mathbf{J}} \underbrace{\left[\begin{array}{l}
x \\
y \\
z
\end{array}\right]}_{\mathbf{x}}
$$

in each iteration the solution is approximated by the following formula

$$
\mathbf{x}_{\text {new }}=\mathbf{x}_{\text {old }}-\mathbf{J}^{-1} \mathbf{f}\left(x_{\text {old }}\right)
$$


where the subscript "new" indicate the value at the new iteration and "old" at the previous iteration. The iterative procedure is continued until convergence of the results is obtained. This procedure has been implemented into an in-house program written in MATLAB (The Math Works, Inc.).

\section{Experimental verification of numerical model}

A schematic view of the experimental setup is shown in Fig. 2a. A reformer made of stainless steel has been placed in an electrical furnace that can be heated up to $1000^{\circ} \mathrm{C}$. The maximum working temperature of the pre-heater and after-heater is $400^{\circ} \mathrm{C}$; however, for all experimental investigations presented in this paper, the temperature of the pre- and after-heater has been kept at $200^{\circ} \mathrm{C}$.
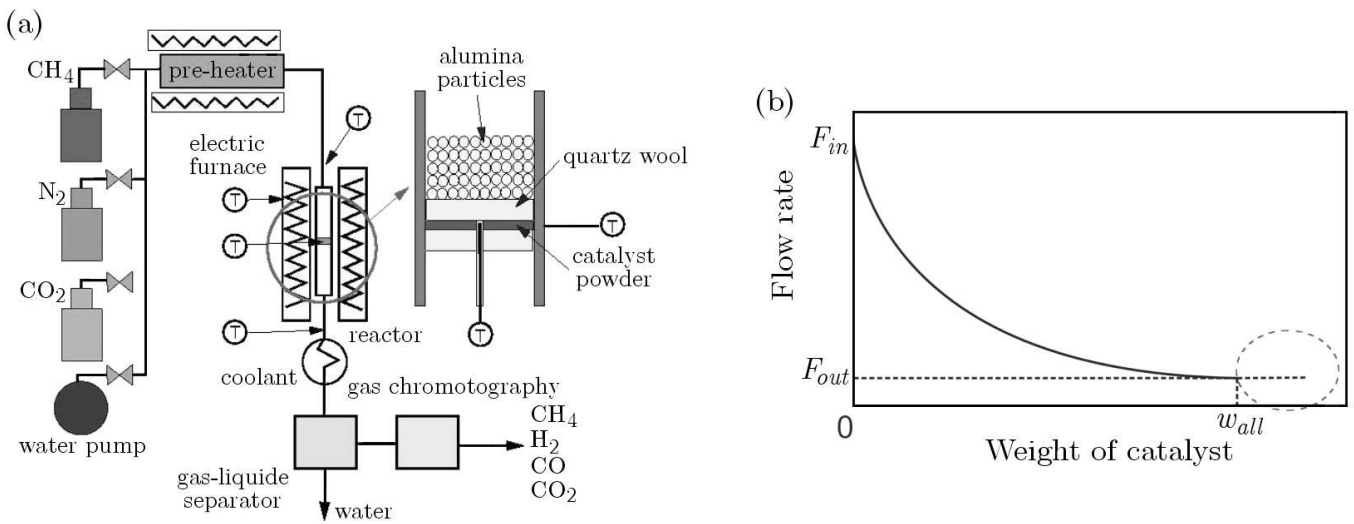

Fig. 2. (a) Schematic view on experimental set-up, (b) kinetic regime and equilibrium regime

High purity methane has been the fuel used in the experiment, with the methane supplied to the reformer via flow controller and an evaporator, which was also used as a pre-heater. Water was fed to the system by a pump. The gas composition after the reforming process was analysed by gas chromatography, before which the steam was separated by cooling down the gas mixture to $2^{\circ} \mathrm{C}$. The reforming reaction tube was filled with $\mathrm{Ru} / \mathrm{Al}_{2} \mathrm{O}_{3}$. Ruthenium-supported alumina is a new type of the catalyst material used in methane/steam reforming reactions. It is spherical in shape and has a diameter of $3 \mathrm{~mm}$; density of $\mathrm{Ru}-\mathrm{Al}$ is $0.0025 \mathrm{~g} / \mathrm{mm}^{3}$. In the presented investigation, the original spherical shape particles were crushed into micro-particles of about $300 \mu \mathrm{m}$ and were located in the reaction tube. A mixture of gases was pre-heated by electric furnace to the reaction temperature before arriving at the reaction zone. To control the thermal conditions of the experiment, four thermocouples were located in the experimental setup, as shown in Fig. 2a.

Figure $2 \mathrm{~b}$ presents the relation between the molar flow rate of methane and the weight of the catalyst. As can be seen for the given inlet flow rate of methane, increasing the amount of catalyst results in a decrease in the methane outlet flow rate as an effect of the higher conversion rate of methane. However, for some amount of the catalyst, marked on Fig. $2 \mathrm{~b}$ as $w_{e q}$, there is no further change in the conversion rate. The equilibrium occurs and the outlet flow rate stays at constant level. Following Itoh et al. (2008), the methane conversion rate $x$ is determined by the outlet quantity and can be calculated as

$$
x=\frac{m_{\mathrm{CO}}+m_{\mathrm{CO}_{2}}}{m_{\mathrm{CO}}+m_{\mathrm{CO}_{2}}+m_{\mathrm{CH}_{4}}}
$$

where $m_{\mathrm{CO}}, m_{\mathrm{CO}_{2}}$ and $m_{\mathrm{CH}_{4}}$ are the mole fractions of the chemical species measured by gas chromatography. 
The methane output flow rate has been measured for the several different catalysts used in the experiment. It was found that for an inlet flow rate of methane of $50 \mathrm{ml} / \mathrm{min}$, steam $S C=3.0$ and catalyst weight of $9.98 \mathrm{~g}$ of $\mathrm{Ru}$ there was no more change in the conversion rate of methane as the amount of the catalyst is increased. It was therefore assumed that the reactions occur in thermodynamic equilibrium for all used experimental conditions. The experimental measurements have been compared with the theoretical calculations of the equilibrium state and good agreement has been found (Fig. 3a and 3b). Therefore, the developed numerical model has been used to numerically analyze the methane/steam reforming process to address the problem of carbon formation.
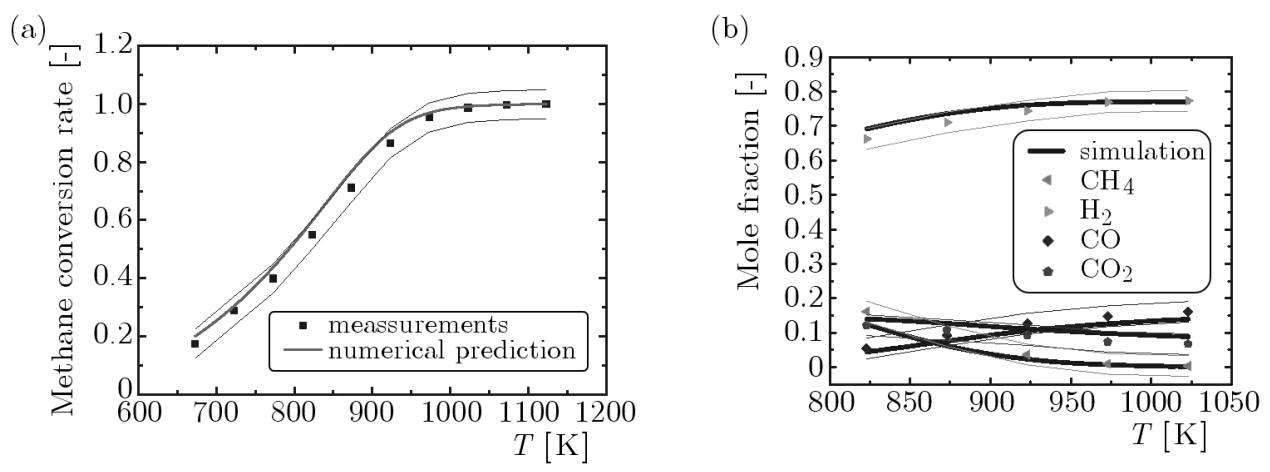

Fig. 3. (a) Calculated conversion rate of methane versus experimental measurements, (b) calculated gas composition versus experimental measurements

\section{Results and discussion}

Numerical simulation is a useful tool in the design process of SOFC reformers and optimisation of the entire methane/steam reforming process. In the numerical model presented in this paper, the equilibrium gas composition can be predicted based on the inlet conditions and the reaction temperature. The verification is conducted for the case where the methane was feed to the system together with steam. The $\mathrm{CO}_{2}$ was not fed directly to the reformer, but it was a product of the shift reaction. Therefore all three reactions; (2.1), (2.2) and (2.3), take place. Our study includes the effect of inlet conditions, and the reaction temperature on the boundary of carbon formation. In particular, the addition of steam to the biogas fuel.
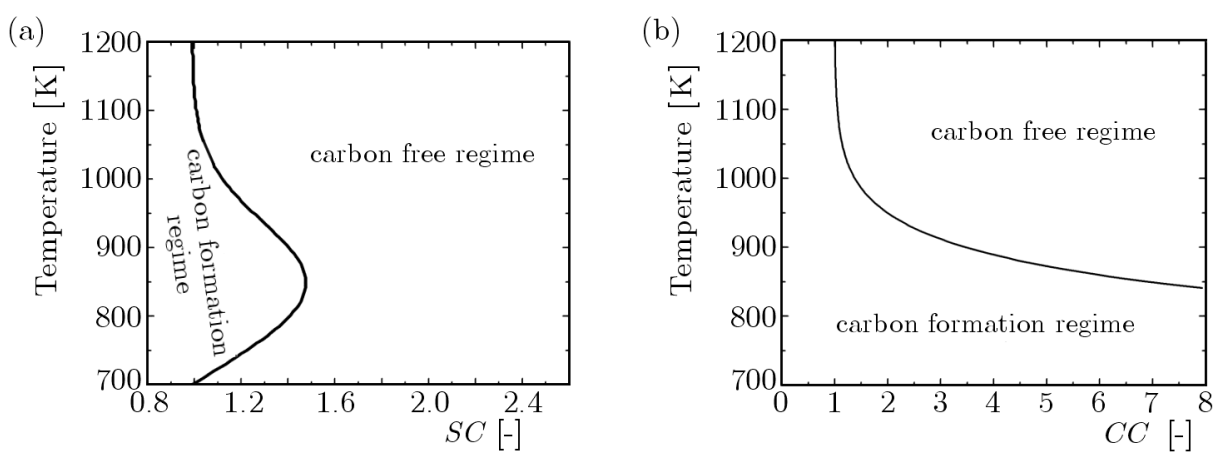

Fig. 4. Carbon deposition regime for methane reforming with steam for different reaction temperatures and $S C$ ratios

To select the carbon deposition regime, the initial values of $S C$ and $T$ were varied and the corresponding values of the parameter $\alpha$ calculated (Eqs. (2.8)). The results of the numerical computation are presented in Fig. 4a. The data indicates that carbon formation can be minimised by increasing the $S C$ ratio or by increasing the temperature of the process. Carbon deposition 
can also be minimised by suppressing the reaction temperature, as shown in Fig. 4a. However, at low reaction temperatures, the conversion rate is relatively low and the synthetic gas mixture produced is an impoverishment of hydrogen and carbon monoxide.

An analogous procedure has been applied to the dry reforming of methane. The carbon deposition regime was selected by changing the initial values of $C C$ and $T$ and calculating the corresponding values of $\alpha$ (Eqs. (2.8)). The results of numerical computation are presented in Fig. 4b. The data indicates that for low temperatures, the dry reforming reaction cannot be conducted without carbon deposition. The dry reforming reaction can proceed reasonably for temperatures above $1000 \mathrm{~K}$ and $C C$ ratios within the range 1.5-2.

Examples of numerical computation of the carbon chemical activity are presented in Fig. 5. Figure 5 presents carbon deposition regimes for the reforming process of different biogas fuels with the addition of steam. As a reference, the case when pure methane was used is presented in Fig. 5a. As is evident in Fig. 5, the amount of carbon dioxide in the fuel has a retarding effect on carbon deposition for the high temperature range 1100-1200 K, where the reforming process can be conducted with only a small amount of steam as in the case with a fuel composition of $50 \% \mathrm{CO}_{2}$ and $50 \% \mathrm{CH}_{4}$ (Fig. 5c) or without steam at all as in the case with a fuel composition of $75 \% \mathrm{CO}_{2}$ and $25 \% \mathrm{CH}_{4}$ (Fig. $5 \mathrm{~d}$ ). The opposite effect can be found for the temperature range $800-900 \mathrm{~K}$, where the amount of steam required for the reforming process is significantly higher than what is needed with the steam reforming of pure methane.
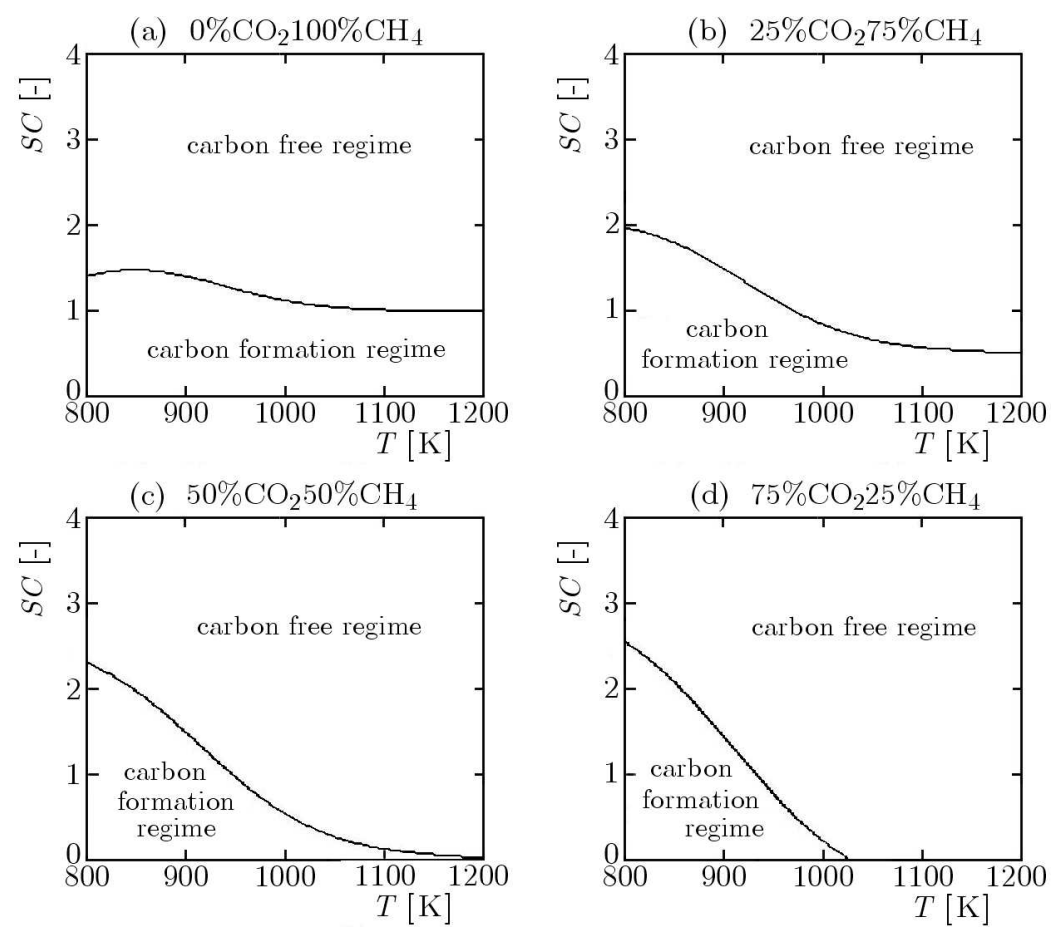

Fig. 5. Carbon formation regime as a function of the $S C$ ratio and temperature

The amount of carbon monoxide present in the synthetic gas is important because, in contrast to low temperature fuel cells, the carbon monoxide does not poison the high-temperature solid oxide fuel cell anode but can be electrochemically converted as a fuel (Achenbach and Riensche, 1994; Achenbach, 1994). The optimal working conditions for the methane/steam reforming process are those that yield the highest methane conversion rate while at the same time giving a fuel rich in hydrogen and carbon monoxide. However, as was previously reported in (Sucipta et al., 2007) and (Jiang and Virkar, 2003), a higher concentration of CO in the fuel significantly reduces the efficiency both in the SOFC module and the hybrid system (Sucipta 
et al., 2007). This can be attributed to the lower heating values and the change in the Gibbs free energy of CO (Sucipta et al., 2007), resulting in a slightly lower cell temperature, which reduces the cell voltage (Sucipta et al., 2007). Jiang and Virkar (2003) reported that although carbon monoxide does not poison a SOFC anode, it exhibits low electrochemical activity with nickel and a high concentration polarisation. It was concluded that carbon monoxide is not an ideal fuel for SOFC if high power densities are required (Jiang and Virkar, 2003). Other research groups indicated that the electrochemical oxidation rate of $\mathrm{H}_{2}$ is twice as high as that reported for CO (Yakabe et al., 2000).

Recent research by Penchini et al. (2013) showed that the losses can be minimised when a mixture of $\mathrm{H}_{2}$ and $\mathrm{CO}$ is fed to the system together with steam or carbon dioxide (Penchini et al., 2013). It was also indicated that carbon deposition is a significant problem when hydrogen is fed to the system together with carbon monoxide (Penchini et al., 2013). Optimising the fuel composition to high hydrogen/carbon monoxide ratios is therefore of paramount importance. Therefore, a numerical computation has been conducted to obtain the $\mathrm{CO}$ and $\mathrm{H}_{2}$ content in the reaction products. Initially, it has been assumed that methane is fed into the system without the addition of steam and with the addition of $\mathrm{CO}_{2}$ (dry reforming of biogas). In the dry reforming case, the initial values of the reaction temperature and the ratio of carbon dioxide to methane $(C C)$ were varied, and the corresponding values of the mole fraction of hydrogen and carbon monoxide were calculated. The results of these numerical computations are presented in Figs. 6b and 6a. As can be seen in Figs. 6b and 6a, hydrogen is not the main product of the reaction. These computations as well as previously published data (Bradford and Vannice, 1996) indicate that the dry reforming reaction is strongly influenced by the simultaneous reverse water gas shift reaction (RWGS) resulting in a $\mathrm{H}_{2} / \mathrm{CO}$ ratio different than unity (Bradford and Vannice 1996), and therefore carbon monoxide production dominates the dry reforming process.
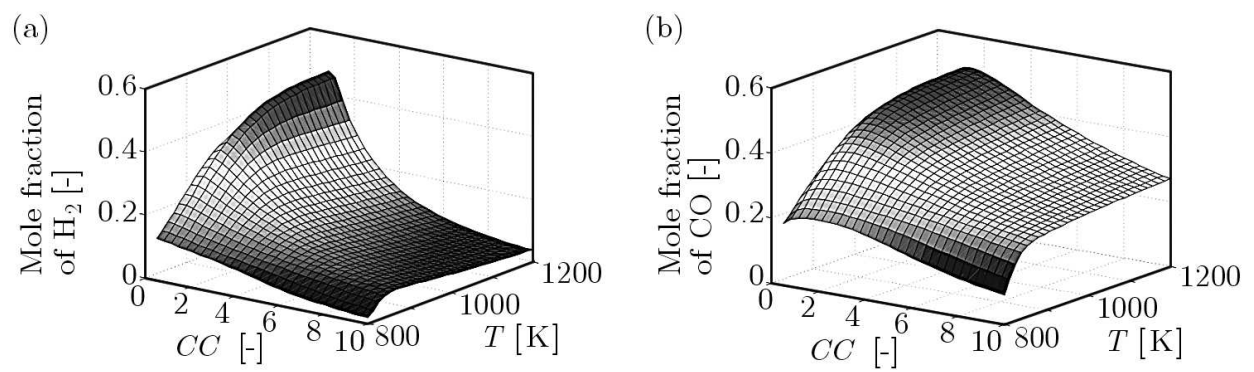

Fig. 6. Mole fraction of (a) hydrogen and (b) carbon monoxide as a function of the temperature and $C C$ ratio

To investigate the influence of the addition of steam on the reforming of biogas, the initial value of the reaction temperature and steam-to-methane ratios have been varied and the corresponding values for the mole fraction of hydrogen and carbon monoxide have been calculated. An example of the numerical results is presented in Fig. 7. As a reference, the case when pure methane is used is presented in Fig. 7a. As is evident in Fig. 7, carbon dioxide content has a weak influence on the total mole fraction of $\mathrm{CO}$ and $\mathrm{H}_{2}$ in the reaction products. A significant change can be observed only for pure methane with small steam-to-methane ratios, which is associated with the suppression of any of the three reactions with a lack of steam and carbon dioxide (see Fig. 7a).

Figure 8 presents the hydrogen content in the reaction products as a function of the temperature, steam-to-methane ratio, and fuel composition. As a reference, the case when pure methane is used is presented in Fig. 8a. As can be seen, the mole fraction of hydrogen decreases with increasing $\mathrm{CO}_{2}$ content in the fuel. It can also be seen that the hydrogen content can vary from roughly from $\sim 0.3$ (see Fig. 8a) to $\sim 0.7$ (see Fig. 8d) of the $\mathrm{H}_{2}$ mole fraction. By comparing 
(a)

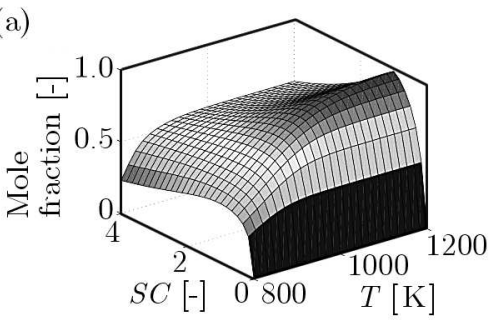

(c)

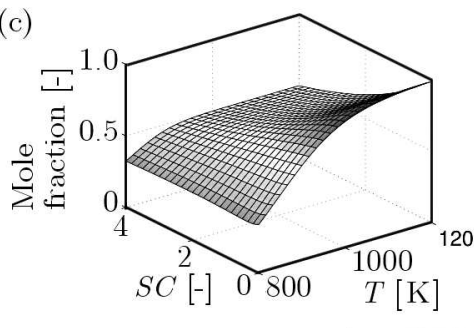

(b)

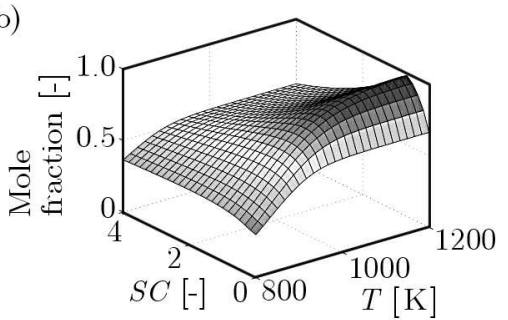

(d)

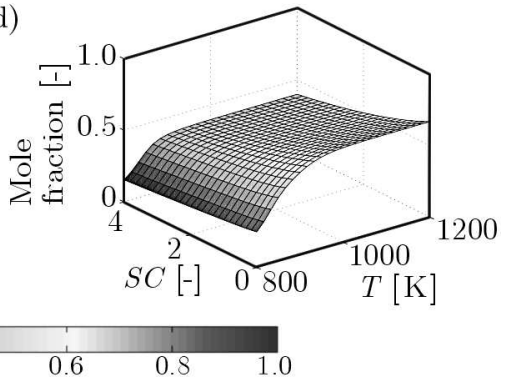

Fig. 7. Total mole fraction of hydrogen and carbon monoxide as a function of the temperature and and $S C$ ratio; (a) $0 \% \mathrm{CO}_{2} 100 \% \mathrm{CH}_{4}$, (b) $25 \% \mathrm{CO}_{2} 75 \% \mathrm{CH}_{4}$, (c) $50 \% \mathrm{CO} 250 \% \mathrm{CH}_{4}$,

(d) $75 \% \mathrm{CO}_{2} 25 \% \mathrm{CH}_{4}$

(a)

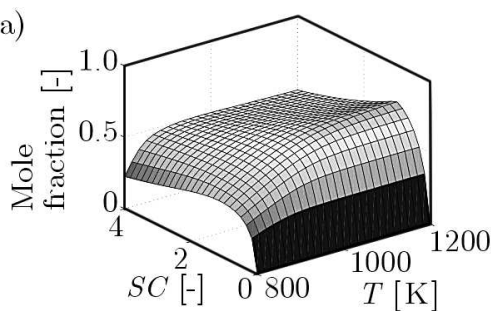

(c)

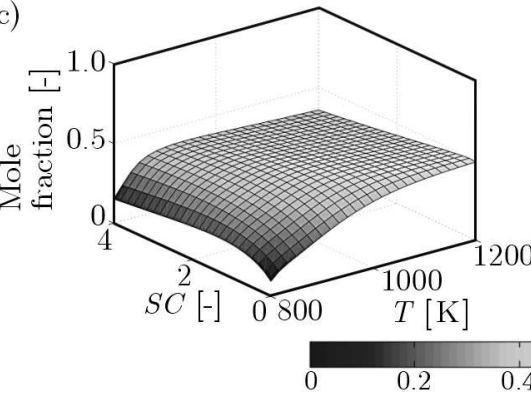

(b)

(d)
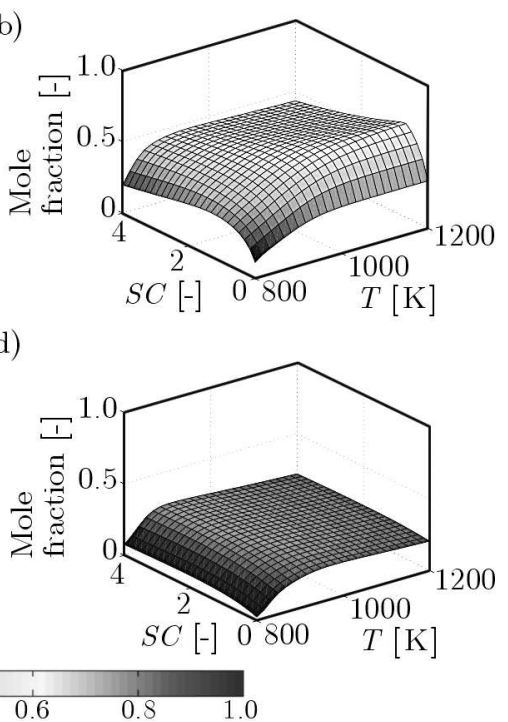

Fig. 8. Mole fraction of hydrogen as a function of the temperature and $S C$ ratio; (a) $0 \% \mathrm{CO}_{2} 100 \% \mathrm{CH}_{4}$, (b) $25 \% \mathrm{CO}_{2} 75 \% \mathrm{CH}_{4}$, (c) $50 \% \mathrm{CO}_{2} 50 \% \mathrm{CH}_{4}$, (d) $75 \% \mathrm{CO}_{2} 25 \% \mathrm{CH}_{4}$

Fig. 8 with Fig. 9, it can be seen that hydrogen is the main product of the biogas reforming process with the addition of steam. However, when the addition of steam is small for a wide range of $\mathrm{CO}_{2}$ content in the fuel, the ratio between the hydrogen and carbon dioxide is close to unity.

Figure 9 presents the carbon monoxide content in the reaction products as a function of the temperature, the steam-to-methane ratio, and the fuel composition. As a reference, the case when pure methane was used is presented in Fig. 9. It can be seen that the maximum carbon monoxide content can vary from around $\sim 0.05$ (see Fig. 9a) to $\sim 0.5$ (see Fig. 9d) of the CO mole fraction. It is evident that the carbon monoxide content increases with the carbon dioxide content of the fuel. It is also clear that the addition of steam suppresses the production of carbon monoxide by shifting the shift reaction to the right side. 


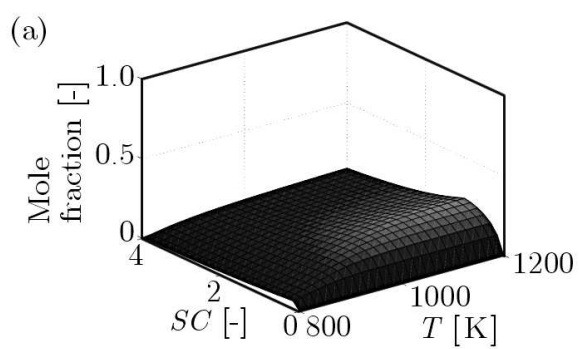

(c)

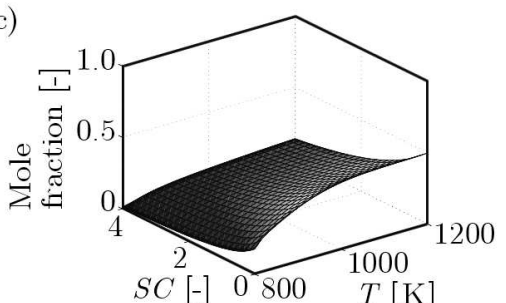

(b)

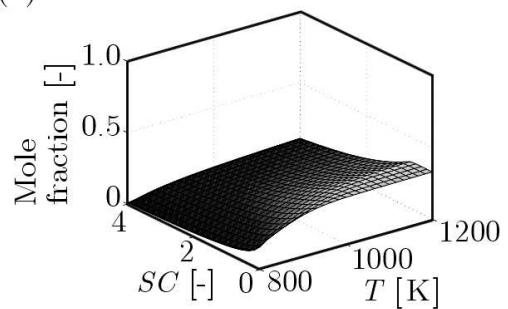

(d)

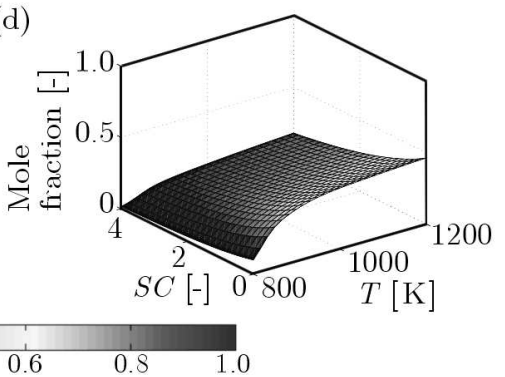

Fig. 9. Mole fraction of carbon monoxides a function of the temperature and $\mathrm{SC}$ ratio; (a) $0 \% \mathrm{CO}_{2} 100 \% \mathrm{CH}_{4}$, (b) $25 \% \mathrm{CO}_{2} 75 \% \mathrm{CH}_{4}$, (c) $50 \% \mathrm{CO}_{2} 50 \% \mathrm{CH}_{4}$, (d) $75 \% \mathrm{CO}_{2} 25 \% \mathrm{CH}_{4}$

\section{Conclusion}

Steam reforming of biogas is an interesting option for high temperature solid oxide fuel cell applications. It has been demonstrated that for a high temperature range, starting from around $\sim 1100 \mathrm{~K}$ to $1200 \mathrm{~K}$, the reaction can be conducted safely outside the carbon deposition regime even with a small amount of steam added to the fuel. However, when steam is added, the main product is hydrogen, and elsewhere the addition of carbon dioxide results in the production of mainly carbon monoxide. However, both gases can be electrochemically converted as a fuel, but a high concentration of $\mathrm{CO}$ compared to $\mathrm{H}_{2}$ can result in a decrease in the overall SOFC efficiency.

\section{Acknowledgments}

This work was supported by the National Centre for Research and Development (Project HTRPL, Contract No. SP/J/1/166183/12).

\section{References}

1. Achenbach E., 1994, Three-dimensional and time-dependent simulation of a planar solid oxide fuel cell stack, Journal of Power Sources, 49, 1, 333-348.

2. Achenbach E., Riensche E., 1994, Methane/steam reforming kinetics for solid oxide fuel cells, Journal of Power Sources, 52, 2, 283-288

3. Assabumrungrat S., Laosiripojana N., Pavarajarn V., Sangtongkitcharoen W., Tangutmatee W., Praserthdam P., 2005, Thermodynamic analysis of carbon formation in a solid oxide fuel cell with a direct internal reformer fuelled by methanol, Journal of Power Sources, 139, 1, 55-60

4. Assabumrungrat S., Laosiripojana N., Piroonlerkgul P., 2006, Determination of the boundary of carbon formation for dry reforming of methane in a solid oxide fuel cell, Journal of Power Sources, 159, 2, 1274-1282

5. Berman A., Karn R.K., Epstein M, 2005, Kinetics of steam reforming of methane on $\mathrm{Ru} / \mathrm{Al}_{2} \mathrm{O}_{3}$ catalyst promoted with Mn oxides, Applied Catalysis A: General, 282, 1, 73-83 
6. Bradford M.C.J., Vannice M.A., 1996, Catalytic reforming of methane with carbon dioxide over nickel catalysts. II Reaction kinetics, Applied Catalysis A: General, 142, 1, 97-122

7. Brus G., Komatsu Y.,Kimijima S., Szmyd J.S, 2012, An analysis of biogas reforming process on Ni/YSZ and Ni/SDC catalysts, International Journal of Thermodynamics, 15, 1, 43-51

8. Claridge J.B., Green M.L.H., Tsang S.C., York A.P.E., Ashcroft A.T., Battle P.D., 1993, A study of carbon deposition on catalysts during the partial oxidation of methane to synthesis gas, Catalysis Letters, 22, 4, 299-305

9. Da Silva A.L., De Fraga Malfatti C., Möller I.L., 2009, Thermodynamic analysis of ethanol steam reforming using Gibbs energy minimization method: a detailed study of the conditions of carbon deposition, International Journal of Hydrogen Energy, 34, 10, 4321-4330

10. Effendi A., Hellgardt K., Zhang Z.G., Yoshida T., 2005, Optimising $\mathrm{H}_{2}$ production from model biogas via combined steam reforming and CO shift reactions, Fuel, 84, 7, 869-874

11. JiAng Y., ViRKAR A.V., 2003, Fuel composition and diluent effect on gas transport and performance of anode-supported sofcs, Journal of the Electrochemical Society, 150, 7, A942-A951

12. Kolbitsch P., Pfeifer C., Hofbauer H., 2008, Catalytic steam reforming of model biogas, Fuel, 87, 6, 701-706

13. Murray M. L., Seymour E.H., Rogut J., 2008, Stakeholder perceptions towards the transition to a hydrogen economy in Poland, International Journal of Hydrogen Energy, 33, 1, 20-27

14. Nishino T., Szmyd J.S., 2010, Numerical analysis of a cell-based indirect internal reforming tubular SOFC operating with biogas, Journal of Fuel Cell Science and Technology, 7, 5

15. Osaki T., Horiuchi T., Suzuki K., Mori T., 1997, Catalyst performance of $\mathrm{MoS}_{2}$ and $\mathrm{WS}_{2}$ for the $\mathrm{CO}_{2}$-reforming of $\mathrm{CH}_{4}$ suppression of carbon deposition, Applied Catalysis A: General, 155, 2, 229-238

16. Osaki T., Masuda H., Mori T., 1994, Intermediate hydrocarbon species for the $\mathrm{CO}_{2}-\mathrm{CH}_{4}$ reaction on supported Ni catalysts, Catalysis Letters, 29, 1/2, 33-37

17. Penchini D., Cinti G., Discepoli G., Sisani E., Desideri U., 2013, Characterization of a 100W SOFC stack fed by carbon monoxide rich fuels, International Journal of Hydrogen Energy, 38, 525-531

18. Sucipta M., Kimijima S., Kenjiro S., 2007, Performance analysis of the SOFC MGT hybrid system with gasified biomass fuel, Journal of Power Sources, 174, 1, 124-135

19. Timmermann H., Sawady W., Campbell D., Weber A., Reimert R., Ivers-Tiff E., 2007, Coke formation in hydrocarbons-containing fuel gas and effects on SOFC degradation phenomena, ECS Transactions, 7, 1, 1429-1435

20. Trimm D.L., 1997, Coke formation and minimisation during steam reforming reactions, Catalysis Today, 37, 3, 233-238

21. Xu J., Zhou W., Li ., Wang J., MA J., 2010, Biogas reforming for hydrogen production over a Ni-Co bimetallic catalyst: effect of operating conditions, International Journal of Hydrogen Energy, 35, 23, 13013-13020

22. Yakabe H., Hishinuma M., Uratani M., Matsuzaki Y., Yasuda I., 2000, Evaluation and modeling of performance of anode-supported solid oxide fuel cell, Journal Of Power Sources, 86, 1, 423-431

23. YANG K.L., YANG R.T., 1986, The accelerating and retarding effects of hydrogen on carbon deposition on metal surfaces, Carbon, 24, 6, 687-693

24. York A.P.E., Xiao T.-C., Green M.L.H., Claridge J.B., 2007, Methane oxyforming for synthesis gas production, Catalysis Reviews, 49, 4, 511-560 